\title{
Differences in the Communicative Orientation of L2 Classrooms
}

MARIA FRÖHLICH

Ontario Institute for Studies in Education

NINA SPADA

University of Michigan

PATRICK ALLEN

Ontario Institute for Studies in Education

In recent years, the development of communicative competence has become the explicit focus of numerous second language teaching programs. Although models of communicative competence and principles of communicative language teaching have been discussed extensively in the literature and a variety of communicative materials have been developed, very little research has been carried out to examine the relationship between actual classroom practices and the development of communicative competence.

This article reports on the results of a study which was intended to validate an observation instrument designed to capture differences in the communicative orientation of L2 classroom interaction in a variety of settings. Thirteen classes in four different L2 programs were observed. The observation scheme used in the study contained categories derived from theories of communicative competence, from the literature on communicative language teaching, and from research in first and second language acquisition, which suggests a number of factors thought to influence the language learning process. These observation categories include features of communication typical of classroom interaction as well as of "natural" language outside the classroom. An analysis of the observation data revealed differences in the communicative orientation of the four types of classrooms.

\section{INTRODUCTION}

In recent years, the development of communicative competence has become the explicit focus of numerous second language teaching programs. Although models of communicative competence (e.g., 
Hymes 1972, Canale and Swain 1980) and principles of communicative language teaching (e.g., Munby 1978, Breen and Candlin 1980, Johnson and Morrow 1981) have been discussed extensively in the literature and a variety of communicative teaching materials (e.g., Byrne 1977, Johnson and Morrow 1979, Fletcher and Hargreaves 1980) have been produced, very little research has been carried out to examine the relationship between actual classroom practices and the development of communicative competence.

Any study which attempts to compare the effects of instructional differences on the development of L2 proficiency must include pretesting, classroom observation, and post-testing. To conduct a process-product study of this kind, at least three prerequisites have to be fulfilled: 1) A model of communicative competence has to be posited; 2) tests to assess learners' communicative competence have to be developed and validated; and 3) observation categories have to be created and pilot-tested to relate what happens in the classroom to learning outcomes.

Within the context of a five-year project in the Modern Language Centre at the Ontario Institute for Studies in Education in Toronto, currently in its third year of research (Allen, Cummins, Mougeon, and Swain 1983), these three issues have been addressed. The concept of L2 proficiency which has been developed posits a componential view of communicative competence which includes grammatical, discourse, and sociolinguistic competence: that is, knowledge of the formal systems of lexis, morphology, syntax, and phonology; knowledge of the ways in which sentences combine into cohesive and coherent sequences; and knowledge of the ways in which language is produced and understood appropriately in different contexts. The underlying assumption is that learners may develop competence in any of these areas relatively independently and that second language programs may differentially affect the development of these components of communicative competence. With respect to the second prerequisite-the development of tests of communicative competence-instruments have been designed to measure the various competencies.

The third task-the design of an appropriate observation schemeis the focus of this article. The article reports the results of a study in which the observation instrument which was developed was pilottested in a variety of instructional settings. It is important to emphasize that this study was not intended to evaluate the second language classes and programs observed, but rather to determine whether this particular observation scheme was capable of capturing differences in the communicative orientation of L2 classrooms.

A large number of observation instruments designed to describe 
and analyze what goes on in the classroom have emerged during the past 30 years (for overviews, see Dunkin and Biddle 1974 and Simon and Boyer 1974). The vast majority of observation schemes are concerned with teacher-student interaction in classrooms in which a subject other than language is taught. The number of observation instruments designed specifically for the second language classroom, where language is not just the medium but also the object of instruction, is much smaller (see Long 1980). The instrument with which we eventually hope to relate L2 classroom events to learning outcomes is referred to as COLT (Communicative Orientation of Language Teaching). The development of the COLT scheme was preceded by a review of various instruments designed to emphasize features which were viewed, on theoretical, empirical, or intuitive grounds, as relevant to the L2 classroom (e.g., Moskowitz 1970, 1971, Fanselow 1977, Naiman, Fröhlich, Stern, and Todesco 1978, Bialystok, Fröhlich, and Howard 1979, Mitchell, Parkinson, and Johnstone 1981, Ullmann and Geva 1982). For an account of the development and revision of the COLT categories, see Allen, Cummins, Mougeon, and Swain (1983).

\section{METHODOLOGY}

\section{The Observation Instrument}

The COLT scheme (see Appendixes A and B) consists of two parts: Part A, which contains categories derived primarily from pedagogical issues in the communicative language teaching literature, and Part B, the categories of which reflect issues in first and second language acquisition research. Part A describes classroom instruction in terms of the types of activities that take place; Part B describes the verbal interactions which take place within activities (for a fuller explanation, see Allen, Fröhlich, and Spada 1984).

Part A contains five major parameters: Activity, Participant Organization, Content, Student Modality, and Materials. These parameters and their subsections were designed to measure the extent to which an instructional treatment may be characterized as communicatively oriented. For example, in the literature on communicative language teaching, considerable discussion is devoted to the value of such elements as the use of authentic materials in the classroom, opportunities for group-work interaction, and emphasis on the formal, functional, discoursal, and sociolinguistic features of the language through meaning-based instruction. Classes which contain these and similar elements are often characterized as being more communicatively oriented than classes which rely on more teacher-centered and form-focused activities. 
Part B analyzes classroom activities at the level of verbal interaction. Seven communicative features were selected to measure use of the target language and the extent to which learners are given the opportunity to produce language without teacher-imposed linguistic restrictions, to engage in sustained speech, to initiate discourse, to react to the meaning of what is being said, to elaborate on one another's utterances, and to exchange unknown or relatively unpredictable information.

\section{Sample}

The study was conducted with a total of thirteen classes, predominantly at the grade 7 level, in four different second language programs: four core French classes, one history and one language arts class in both the extended French and French immersion programs, and five ESL classes. The four program types, the first three of which are characteristic of French as a second language (FSL) education in Canada, can be briefly distinguished as follows:

1. Core French is the regular program, in which the French language is the subject of instruction. In Ontario, French is now compulsory up to grade 10. The starting point and the amount of instruction vary, but on the average, students start in grade 4 or 5, with 20 to 40 minutes of French a day. In Toronto, students normally start in grade 4 , with 40 minutes a day.

2. Extended French includes, in addition to core French, the teaching of one or more school subjects through the medium of the target language.

3. In French immersion programs, French is the medium of instruction in subject-matter classes. At the primary level, programs typically involve half a day of immersion in kindergarten, followed by one or more years of total French instruction. In grade 2 at the earliest, a daily period of English language arts is introduced. By grade 4 or 5, the proportion of the day in English may increase to 50 percent.

4. The ESL classes in the study were "self-contained-students spent all or most of the day with their ESL teacher. In addition to English language instruction, students also received varying amounts of subject-matter instruction. The more typical ESL situation in Toronto is a program in which students are withdrawn from the regular classroom for varying amounts of time to receive primarily language instruction. 
The study was begun with a number of tentative expectations about the main characteristics of the four types of programs. These expectations were based on some preliminary classroom observations; discussions with teachers, consultants, and school board officials; and a review of textbooks and other teaching materials. Core French is taught as a subject within a limited time period, and classes in this program were expected to contain a relatively large proportion of form-focused, teacher-centered activities. Since extended French involves the presentation and discussion of subjectmatter material in addition to core French instruction, the teaching in this program was expected to be somewhat less structured and more meaning-oriented. French immersion is designed for students to receive the same education as they would in the regular English program, except that the medium of instruction is French; French immersion classes were therefore expected to provide greater opportunity for authentic discourse and for the negotiation of significant meaning. ESL teaching in Toronto differs from the three types of French programs, since many more opportunities for English language acquisition exist outside the classroom. As a result, it was expected that ESL teachers would tend to use class time to practice various aspects of the language code but that they would also seek to introduce communicative enrichment material from the "real world outside the classroom whenever possible.

As noted above, the purpose of the study was to validate the observation instrument, rather than to evaluate the programs themselves. The reason for including classes from different L2 programs was to ensure that the COLT categories were capable of describing activities in a range of instructional settings. No claim is being made at this stage that the classes selected constituted a representative sample from each program type.

\section{Procedures}

Each class was visited twice by two observers. The observation period per visit varied from 30 to 100 minutes, depending on the length of the lesson. In one ESL class, however, instruction was totally individualized; that is, the students were working on different topics, with different teaching materials, for varying lengths of time. For this reason, only one of the Part A parameters, Participant Organization, could be reliably observed for this class. Therefore, with the exception of Table 1, the tables in this article which refer to Part A of the COLT report on the results of 12 classes only. All classes, with the exception of the one ESL class already mentioned, 
were recorded on audiotape; thus, results for Part B are also based on 12 classes.

Part A of the COLT scheme (see Appendixes A and B) was used during the classroom observations. The parameters and categories of Part A describe instruction at the level of activity. All coding in Part A was done in real time-that is, during the observation period-by the two observers present in the classroom. In addition to identifying the Activity (e.g., drill, dialogue, repetition drill, conversation), the observers placed a check mark in the appropriate boxes under each of the other four major headings: Participant Organization, Content, Student Modality, and Materials. In the course of a single activity, several categories might be marked under each of these four main headings. For example, under the heading Participant Organization, there might be instances of student-tostudent interaction, teacher-to-student interaction, and teacher-toclass interaction. In such cases, check marks were placed in the boxes for each of the appropriate Participant Organization categories, and a circle was drawn around the check mark which represented the primary focus or predominant feature of the activity. This procedure was followed for all Part A categories.

Part B coding (see Appendixes A and B), done after the lesson, was based on the audiotape recording of the class, A time-sampling procedure within each activity identified in Part A was followed. Coding started at the beginning of each activity, lasted for one minute, and was resumed after a two-minute interval. During the one-minute coding periods, the frequency of occurrence of each category of the communicative features of teacher and student interaction was recorded by two coders.

Although the coding of Part A and Part B was carried out independently, the coders checked their entries for Part A immediately after each observation period and their entries for Part B after each minute of coding. Wherever necessary in coding Part B, the tape was replayed, and any problems were discussed. For this reason, it was not considered necessary to calculate interceder reliability coefficients. In any future study, however, interceder agreement will be determined statistically.

\section{ANALYSIS AND FINDINGS PART A}

Initial analysis of the Part A data consisted of calculating the

1 Parts of some of the recordings made in classes where group work was being conducted were unusable. If, in the future, group work is to be observed, several tape recorders may be necessary, or the microphones may have to be moved from one group to another at regular intervals instead of keeping them in one position during the entire class period. 
percentage of classroom time spent on the individual categories under each of the four major headings. These calculations were carried out separately for each visit. Subsequently, tables were prepared to present the average percentage of observation time coded for various categories by class and by program.

To illustrate, let us consider two hypothetical visits to Class 1 and Class 2 in Program X. During the first visit, Class 1 spent 10 minutes in group work, and for the remaining 20 minutes the teacher interacted with individual students or the whole class $(\mathrm{T} \longrightarrow \mathrm{S} / \mathrm{C})$. During the second visit, the class spent 15 minutes in whole-class interaction and 15 minutes in group work. In Class $2, \mathrm{~T} \longrightarrow \mathrm{S} / \mathrm{C}$ interaction was coded as the dominant activity for the whole class during both visits. The following calculations were carried out:

\section{Participant Organization-Percentage of Time by Visit}

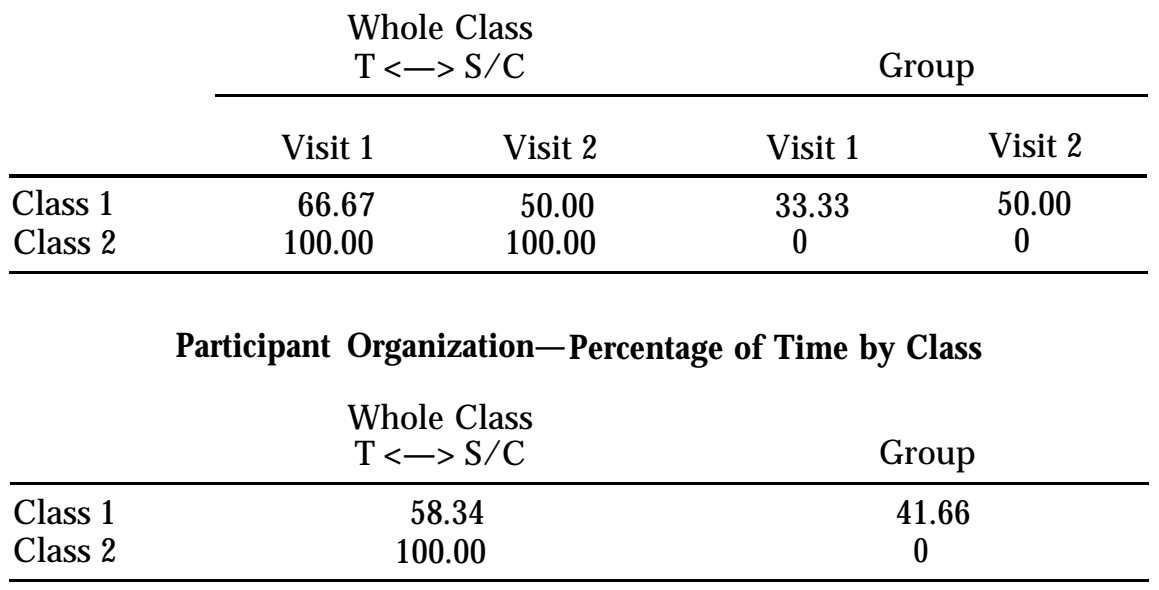

Participant Organization-Percentage of Time by Program

\begin{tabular}{cc}
$\begin{array}{c}\text { Whole Class } \\
\mathrm{T} \leftrightarrow \mathrm{S} / \mathrm{C}\end{array}$ & Group \\
\hline 79.17 & 20.83 \\
\hline
\end{tabular}

The primary category checked off during an activity always received credit for the entire length of time that the activity lasted, just like one which occurred exclusively. For example, during an activity in which the teacher and students were interacting meaningfully, the occasional choral repetition of a word or phrase would not 
be recorded. Therefore, only those categories recorded as the exclusive or primary feature of an activity are presented in the following tables.

\section{Participant Organization}

For this first major heading, percentages were calculated for the following categories: Whole Class, Group Work, Individual Seat Work, and the combination of Group Work/Individual Work. Whole Class is further subdivided as follows: teacher interacting with individual students or the entire class $(T \longrightarrow S / C)$, students interacting with the class or individual students while one central activity is going on $(\mathrm{S} \longrightarrow \mathrm{S} / \mathrm{C})$, and Choral Work. The mean percentages by program are shown in Table 1 .

TABLE 1

Participant Organization Mean Percentages of Observed Time by Program

\begin{tabular}{lcccccc}
\hline \hline & \multicolumn{3}{c}{ Whole Class } & & & \\
\cline { 2 - 4 } & $\mathrm{T} \leftrightarrow \mathrm{S} / \mathrm{C}$ & $\mathrm{S} \leftrightarrow \mathrm{S} / \mathrm{C}$ & Choral & Group & Individual & $\begin{array}{c}\text { Group/ } \\
\text { Individual }\end{array}$ \\
\hline $\begin{array}{l}\text { Core } \\
\text { French (4) }\end{array}$ & 58.49 & 2.72 & 14.40 & 5.01 & 19.38 & 0 \\
$\begin{array}{l}\text { Extended } \\
\text { French (2) }\end{array}$ & 70.48 & 17.20 & 0 & 0 & 12.32 & 0 \\
$\begin{array}{l}\text { French } \\
\text { Immersion (2) }\end{array}$ & 60.90 & 17.32 & 2.73 & 0 & 19.05 & 0 \\
ESL (5) & 21.28 & 11.05 & 1.28 & 10.00 & 43.02 & 13.37 \\
\hline
\end{tabular}

As previously stated, the study was begun with various expectations about which categories would best describe the four types of programs. In core French, the expectation was that there would be a great deal of whole-class interaction with the teacher addressing either the whole class or individual students, as well as a substantial amount of choral work. Whole-class interaction, but not choral work, was thought to be a likely characteristic of extended French and French immersion programs. In the ESL classes, more group work than whole-class interaction was expected.

The data support these expectations to the extent that all the FSL programs were characterized by a considerable amount of wholeclass interaction. However, the expectation about choral work in 
core French was not supported, since the core French mean of 14.4 percent for Choral Work was largely attributable to one particular class. In the ESL classes observed, individual seat work-and not group work, as expected-predominated.

\section{Content}

The Content parameter describes the subject matter of the activities-in other words, what is being talked about, read, written about, or listened to. The categories and subcategories of Content in the COLT observation scheme are as follows (see Appendix A for definitions; Topic Control is discussed separately at the end of this section):

Management

Classroom procedures

Disciplinary routines

Explicit focus on language

Form

Function

Discourse

Sociolinguistics

Other topics

Narrow range of reference

Limited range of reference

Broad range of reference

Topic control

Control by teacher

Control shared by teacher and student(s)

Control by student(s)

For these categories, the expectation was that there would be predominant focus on form in core French, focus on form as well as other topics (particularly of limited and broad range) in extended French, and relatively greater focus on meaning than form in French immersion and ESL.

Percentages were calculated first for those categories which had occurred exclusively or had been marked as the primary feature of an activity. For example, during one activity, a teacher might have focused exclusively on grammar (Form). During another activity, Form and Sociolinguistics might have been checked off, but because the teacher had made only a brief reference to sociolinguistic aspects of language use, Form was considered the primary focus. Percentages were then determined for those categories which had 
occurred in combination, that is, in situations in which the observers felt that two categories had received roughly equal emphasis. For example, a core French class was practicing verb endings for the second person singular and plural, with explicit reference to the differences in the use of tu/vous when addressing friends and strangers. Thus, the content of this activity was simultaneously Form and Sociolinguistics.

The mean percentages of total observed time for Content categories and subcategories are presented in Table 2. With the exception of the ESL classes and their unexpectedly strong emphasis on form, the data supported initial expectations. In comparing programs, it becomes apparent that in the core French and ESL classes, more than half of the class time observed involved activities which focused exclusively or primarily on form (58.44 and 66.43 percent, respectively). By contrast, in the extended French and the French immersion classes, the focus on form decreases, and the focus on meaning (i.e., Other Topics) increases (40.55 and 62.53 in extended French and French immersion, respectively).

This shift can be largely attributed to the teaching of subject matter, since subject matter is coded as Other Topics-Broad Range of Reference. It is interesting to note that the extended French program occupies something of a middle position between core French and French immersion; form is given substantial weight (half of the observation time, if combinations are included), although considerably less than in core French and considerably more than in French immersion. However, the difference in the emphasis on form between French immersion and extended French may be attributable in part to the lower proficiency level of the students in the latter program; at the time of the observations, students had been in the extended French program for only a few weeks.

It is also important to note which subcategories of ContentLanguage were seldom or never coded. One is Discourse, which was defined as "explicit focus on the way sentences combine into cohesive and coherent sequences." Although students were exposed to oral and written discourse through listening and reading activities, explicit reference to aspects of cohesion or coherence was never made. Nor was there explicit reference to Function, that is, illocutionary acts. Another category which rarely appeared in the classes observed was Sociolinguistics. The major exception was one of the French immersion classes, in which the language appropriate for journalistic reports and that suitable for advertisements were compared and discussed during an entire lesson.

The last Content category is Topic Control, that is, who selects the 


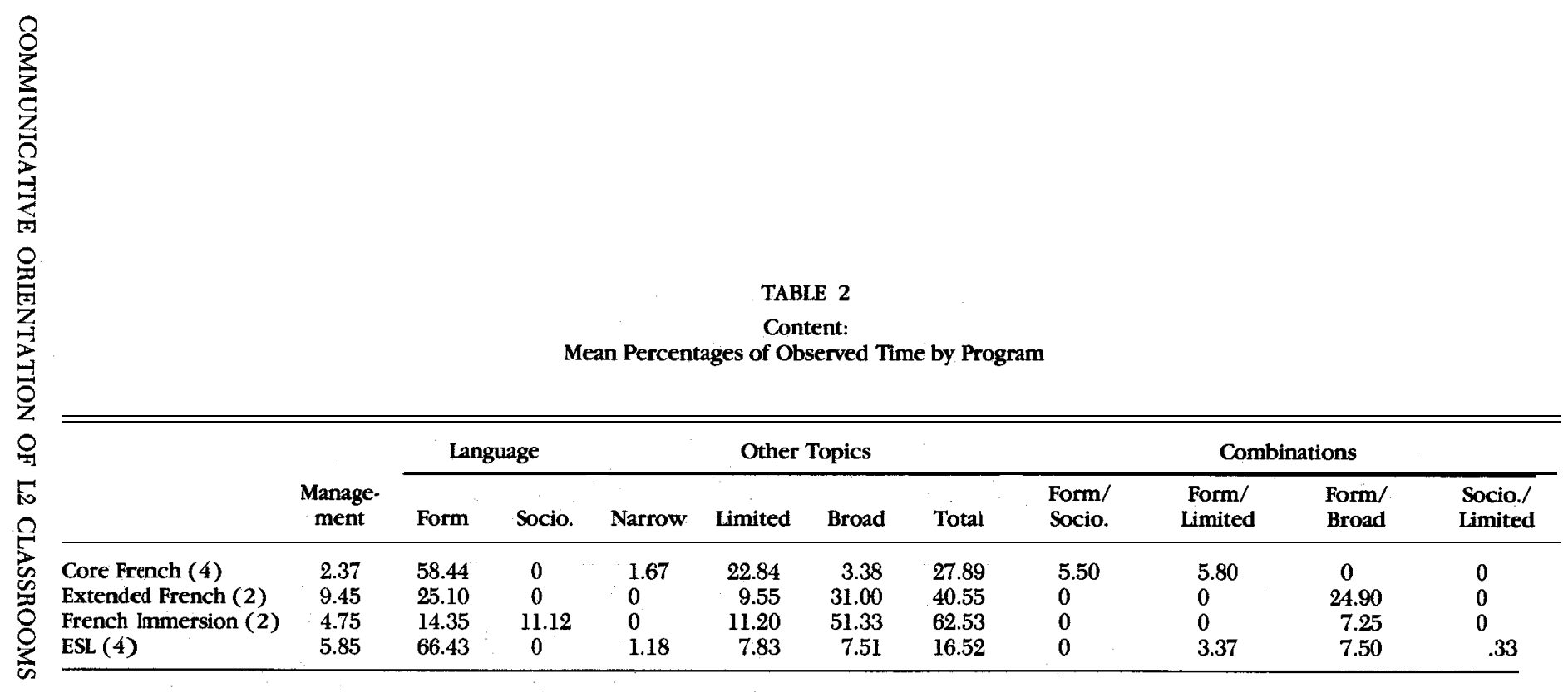


topic and controls what is being read, written, or talked about. ${ }^{2}$ The data for these categories are presented in Table 3.

TABLE 3

Topic Control:

Mean Percentages of Observed Time by program

\begin{tabular}{lccc}
\hline \hline & Teacher & Teacher/Student & Student \\
\hline Core French (4) & 93.89 & 6.11 & 0 \\
Extended French (2) & 88.72 & 11.28 & 0 \\
French Immersion (2) & 80.02 & 19.33 & $\mathbf{. 6 5}$ \\
ESL (4) & 91.08 & 8.92 & 0 \\
\hline
\end{tabular}

As expected, teachers controlled topic selection and content most of the time in all four programs. Again, core French and ESL, which had the two highest percentages for Teacher Control and the two lowest percentages for Teacher/Student Control, appear to be most similar.

\section{Student Modality}

The data for Student Modality-the particular skill or combination of skills involved in a classroom activity-are presented in Table 4 . Although these categories present useful information about the amount of time devoted to listening, speaking, reading, and writing, they provide no insight into how these skills were being developed. Thus, the parameter of Student Modality does not directly address the issue of whether skills practice was more communicatively based in one program than in another. In the COLT, such differences would have to be captured in the open-ended description under Activity.

\section{Materials}

The final major heading in Part A of COLT is Materials. In this report, differences among the programs in type and source of materials are presented.

2 A teacher might select a topic and then give the students a great deal of freedom in developing the topic. For example, "Write a short paragraph about your impressions when you first came to Canada." In such cases, Teacher/Student Control would be checked off.

3 Since the coders found that Use of Materials frequently overlapped with Topic Control, data for the former are not reported in this article. In addition, because it proved difficult to find a satisfactory definition for Use of Materials, this category has been deleted in the revised version of COLT. 
TABLE 4

Student Modality

Mean Percentages of Observed Time by Program

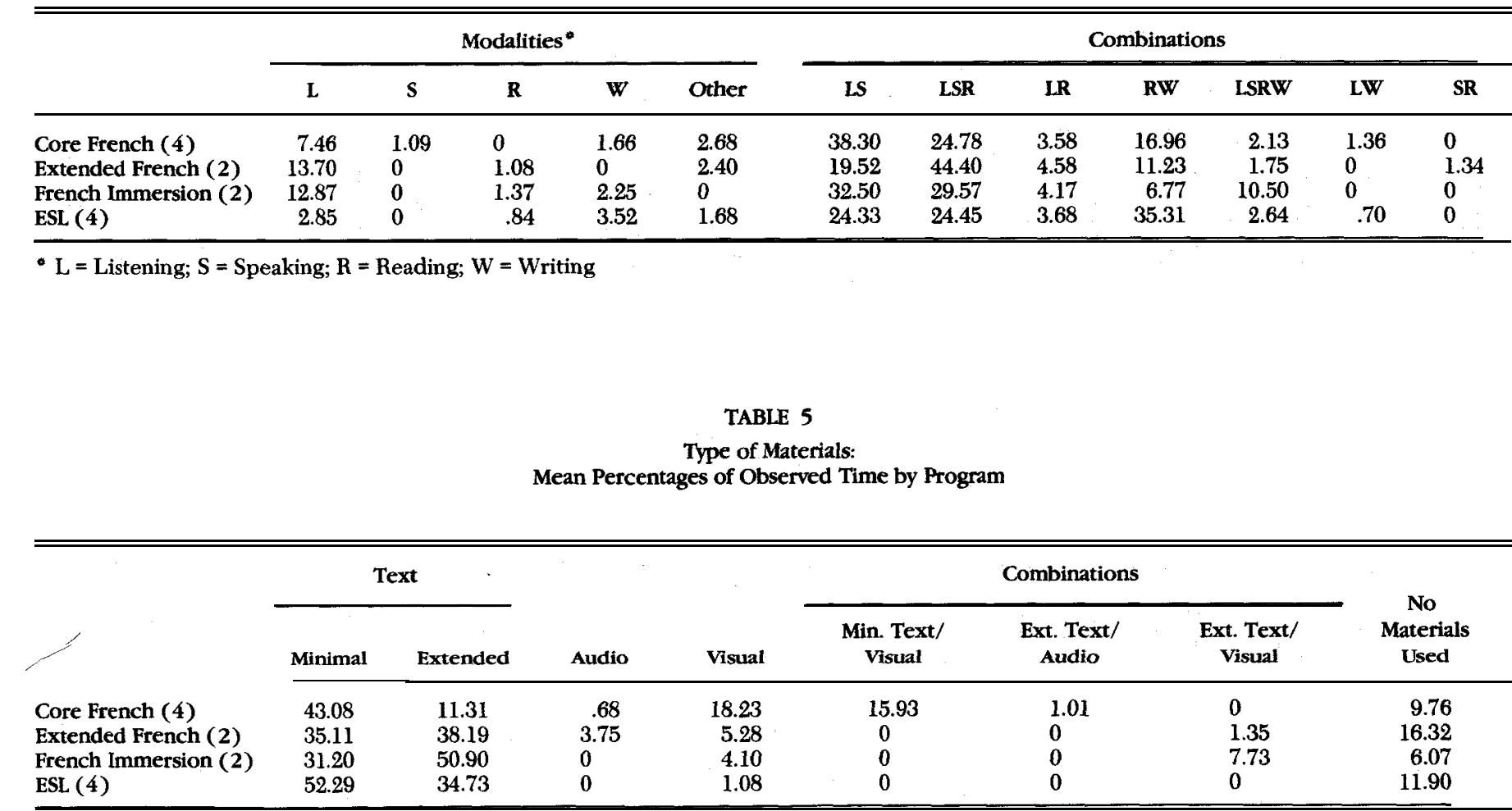


Type. Materials were classified as Text, Audio, or Visual. Since the development of discourse competence may be affected by the extent to which students are exposed to extended written texts rather than to isolated, disconnected sentences, Text was subdivided into Minimal and Extended. Mean percentages by program are presented in Table 5, which shows that text materials were used predominantly in all programs and that visual materials played a substantial role only in core French.

It was expected that the use and production of minimal text would predominate in core French, that a balance between minimal and extended text would be found in ESL and extended French, and that extended text would predominate in French immersion. These expectations were based on the assumption that classes which focused more on teaching the language code would likely include more activities involving minimal texts (e, g., worksheets with grammatical exercises) than would programs which incorporated subjectmatter instruction. With the exception of ESL, the data supported these expectations.

Source. The second category of Materials refers to the origin and purpose of the teaching materials used. Were the materials designed for L2 teaching and learning (Pedagogic), or were they originally intended for some other purpose (Non-Pedagogic) ? A third possibility was that non-pedagogic, or "authentic," materials had been adapted for instructional purposes, in which case they were coded as Semi-Pedagogic.

Table 6 presents data on the source of teaching materials by program. Pedagogic materials made up the largest percentage across all programs. They were used most extensively in core French (83.69

TABLE 6

Source of Materials

Mean Percentages of Observed Time by Program'

\begin{tabular}{lccc}
\hline \hline & Pedagogic $^{2}$ & Semi-Pedagogfc & Non-Pedagogic \\
\hline Core French (4) & 83.69 & 4.90 & 1.69 \\
Extended French (2) & 72.88 & 5.53 & 5.30 \\
French Immersion (2) & 67.56 & 2.25 & 24.13 \\
ESL (4) & 63.99 & 2.84 & 15.75 \\
\hline
\end{tabular}

1 Percentages, calculated from total class time observed, do not add up to 100 percent because materials were not used all the time.

2 These figures also include materials developed for native speakers of the target language:

this applies to the extended French, French immersion, and ESL programs.

3 Data for 5.52 percent of the time observed are missing. 
percent), followed by extended French (72.88 percent), French immersion (67.56 percent), and ESL (63.99 percent). Non-pedagogic materials were used relatively frequently in the French immersion and ESL settings (24.13 and 15.75 percent, respectively) but rarely in the other two programs.

\section{ANALYSIS AND FINDINGS: PART B}

Part B of the COLT observation scheme analyzes the communicative features of verbal interaction during classroom activities. It consists of the following seven features and their categories (see Appendix A for definitions):

Use of target language

Use of L1 or L2

Information gap

Giving information

Predictable or unpredictable

Requesting information

Pseudo or genuine

Sustained speech

Ultraminimal turns

Minimal turns

Sustained turns

Reaction to message/code

Incorporation of preceding utterances

No incorporation

Repetition

Paraphrase

Comment

Expansion

Elaboration

Discourse initiation

Restriction of linguistic form

Restricted

Limited

Unrestricted

All of these features and categories were used for coding teacher and student talk, with the exception of Discourse Initiation and Restriction of Linguistic Form, which were used for coding student talk only.

4 Materials developed for teaching/learning purposes, not for second language learners but for native speakers of the target language, were coded as Pedagogic. This applies particularly to the extended French, French immersion, and ESL programs. In the future, such materials will be coded in a separate category. 
To compare communicative features of verbal interaction across programs, each category in Part B was calculated as a proportion of its feature. For example, in the core French program, the percentage of L2 use within the feature Use of Target Language was .96; the percentage of L1 use was .04. These proportions are presented by program in bar graphs; Figures 1 and 2 present the data for teacher and student verbal interaction, respectively. ${ }^{5}$ In addition to a descriptive comparison, one-way analyses of variance and Duncan Multiple Range Tests were conducted to find out if the differences between programs reached statistical significance.

\section{Teacher Verbal Interaction}

As indicated in Figure 1, teachers used the target language most of the time in all four programs. They generally gave unpredictable information, such as directives or new information. No significant differences between programs were found for these categories.

Teachers did not generally ask genuine questions-that is, questions to which they did not already have the answer. Although differences between programs did not reach statistical significance, it is interesting that the proportion of genuine requests steadily increased from program to program in this order: core French (.16), extended French (.37), French immersion (.42), and ESL (.52).

There were important differences between programs in the feature of Sustained Speech. Teacher turns in core French were rarely sustained; only 28 percent of core French teacher turns were longer than a sentence. As in the case of Genuine Requests, the proportion of sustained teacher speaking turns in classrooms in the other programs increased in this order: core French (.28), extended French (.52), French immersion (.57), and ESL (.61). The difference in the proportion of sustained teacher turns between core French and the remaining three programs was significant $(\mathrm{F}(3,14)=5.37 ; \mathrm{p}$ $<.05)$.

The final communicative feature of teacher talk, Incorporation of Preceding Utterances, reflects how teachers reacted to student utterances. As indicated in Figure 1, teachers in all, programs most frequently used comments such as "Good" and "Right" in reacting to students' utterances; paraphrasing was used the least. One interesting difference among programs involved the use of expansions and elaborations. These types of utterances occurred extremely rarely in

5 For the feature Information Cap, each subcategory (e. g., Giving Unpredictable Information) was calculated as a proportion of the superordinate category (e.g., (living Information), not as a proportion of the feature. 
core French and ESL, but they were used at least to some degree (although the differences were not statistically significant) in extended French and French immersion. Despite the argument that elaborations and expansions contribute to first language development, teachers in this study rarely built on student responses to develop a topic or to engage students in further discourse. It has to be remembered, however, that the sample was extremely small and may not have been representative.

The feature of Reaction to Message/Code occurred extremely rarely in teacher verbal interaction and is thus not included in Figure 1.

\section{Student Verbal Interaction}

As Figure 2 indicates, student verbal interaction was almost always in the target language. However, students generally used the target language only while the teacher exercised control over classroom activities. During seat work, most interaction occurred in the native language. This is not reflected in the present data, since at those times the tape recorder was usually turned off.

Students in core French gave significantly fewer unpredictable responses (.14) than did students in the other three programs $(\mathrm{F}(3,14)=4.38 ; \mathrm{p}<.05)$. The greater proportion of unpredictable responses in extended French (.41) and French immersion (.49) can be partially attributed to the introduction of subject matter (i.e., history). When the focus is on meaning and on topics other than the language code, the opportunities increase for teacher questions which have more than one acceptable answer.

Core French also differed from the other programs in terms of length of student speaking turns. The majority (.58) of student speaking turns in core French were ultraminimal; in the other three programs, student turns were much more often minimal: .56 in extended French, .46 in French immersion, and .44 in ESL. Sustained turns were almost nonexistent (.03) in core French; they increased slightly in extended French (.11) and rose to .29 and .31 in ESL and French immersion, respectively.

The final set of data in Figure 2 reflects the degree of restriction imposed on the linguistic forms which students could use in producing target language utterances. Unrestricted utterances were very infrequent in core French (.07) but increased in this order: ESL (.34), extended French (.47), and French immersion (.71).

The remaining four features-Reaction to Message/ Code, Incorporation of Preceding Utterances, Discourse Initiation, and Requesting Pseudo/Genuine Information-occurred extremely rarely in student 


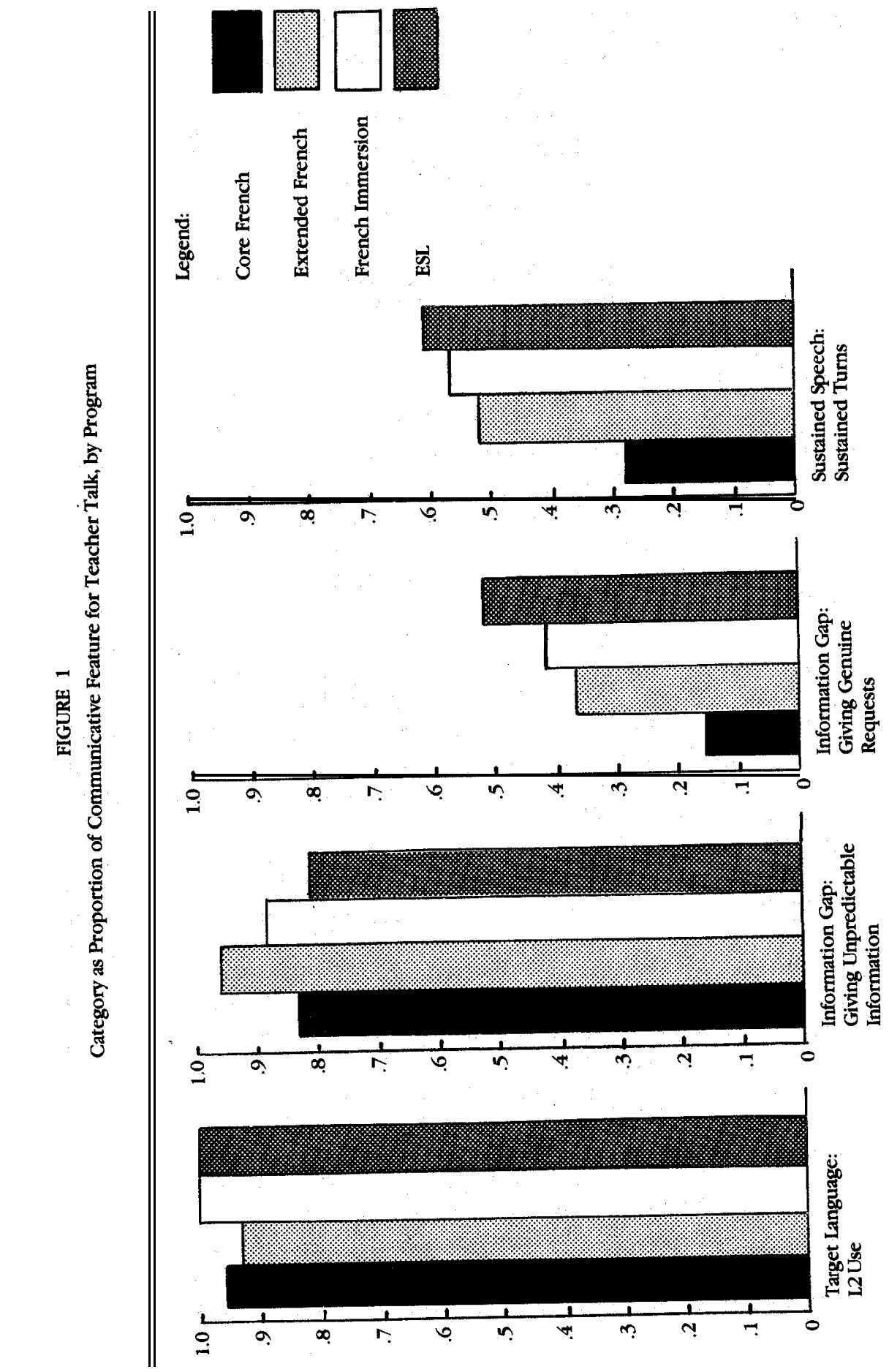



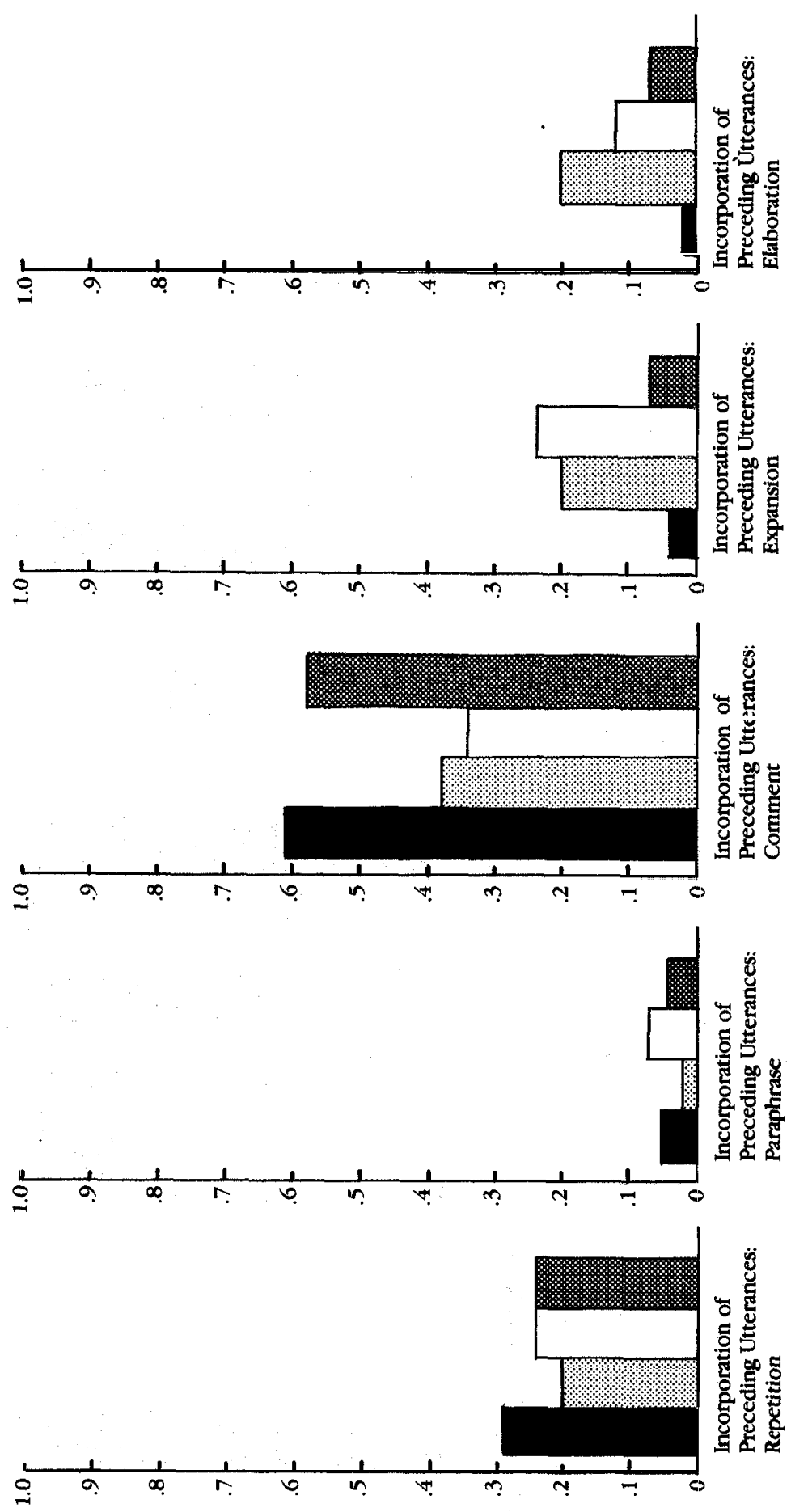

COMMUNICATIVE ORIENTATION OF L2 CLASSROOMS 


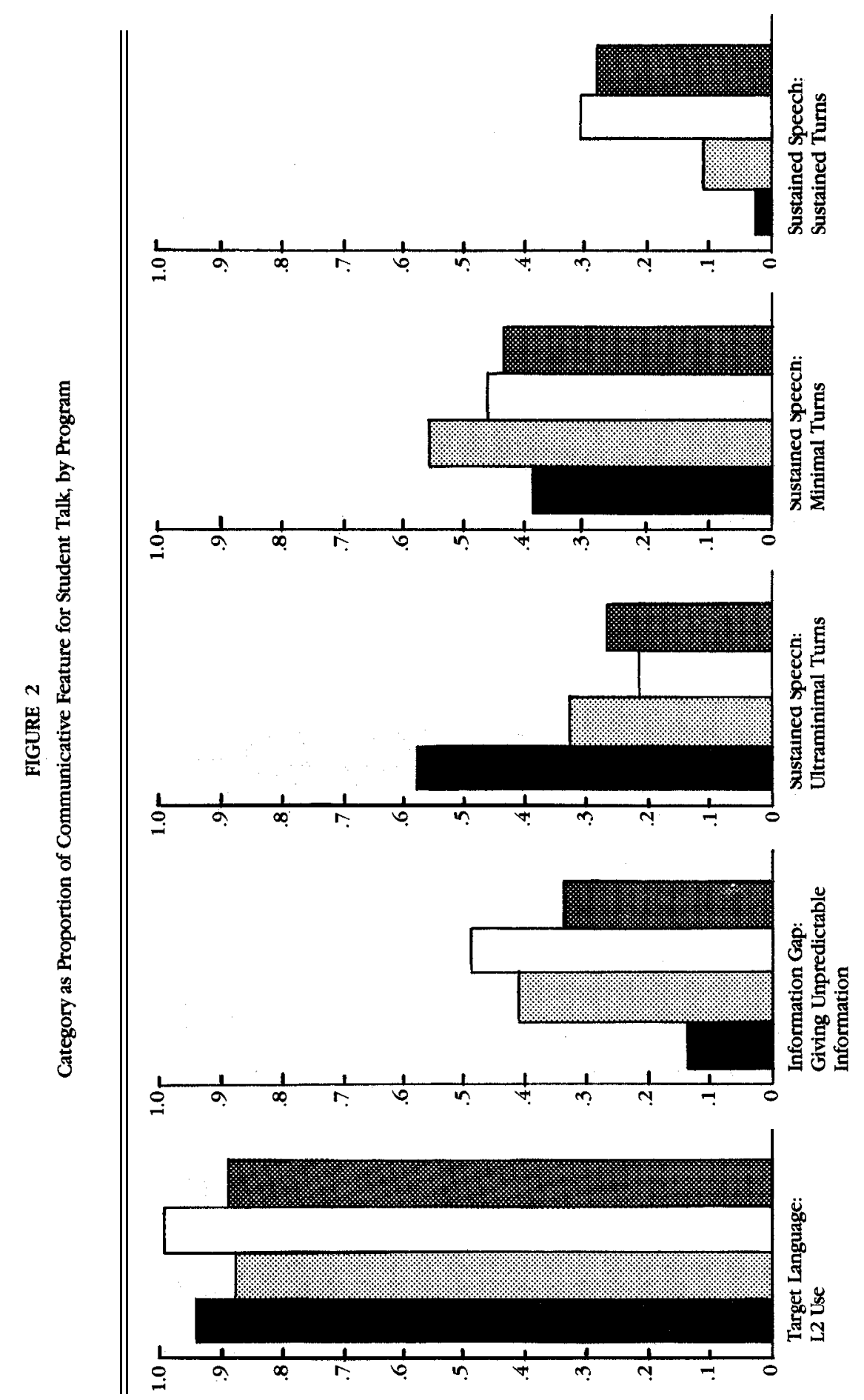



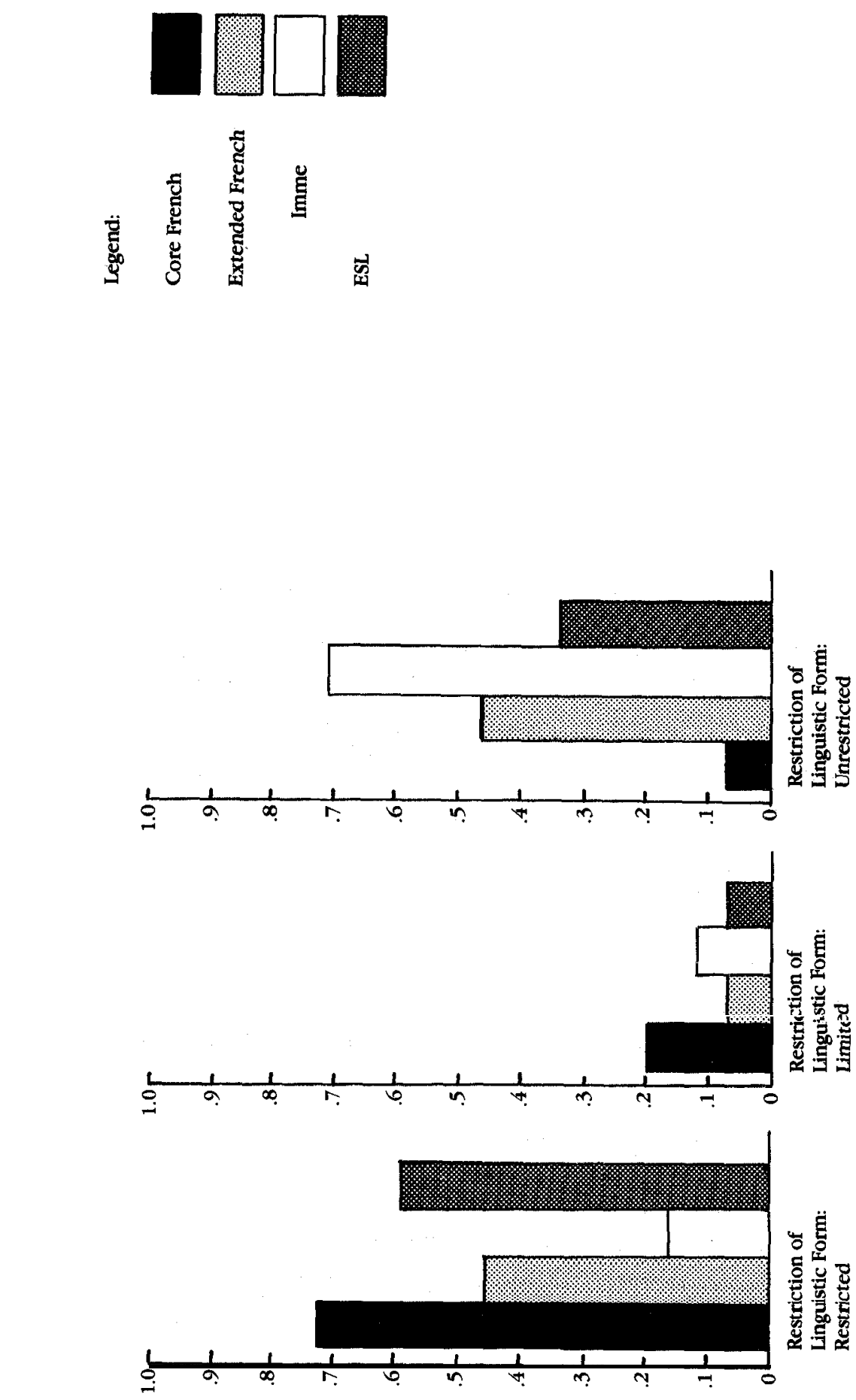

COMMUNICATIVE ORIENTATION OF L2 CLASSROOMS 
verbal interaction in all four programs and are therefore not included in Figure 2.

\section{DISCUSSION}

The data show that many of the descriptive categories introduced in Part A of the COLT are capable of differentiating between the four L2 programs observed. The categories of Content and Materials were particularly revealing in this regard.

Expectations about the distinguishing characteristics of each program were largely supported. The main exception was the ESL program, for which a great deal of group work, in which students would discuss topics other than the language code, was expected. Instead, a strong focus on grammar and vocabulary was found, even during group work, and students were frequently involved in individual seat work which did not foster communication. When communication did take place during seat-work activities, it was generally in the students' first language. One possible reason for the focus on form in the ESL classes is that the ESL learners in this study, unlike the FSL learners, had considerable opportunity for acquisition outside the classroom and that because of this, the ESL teachers may have felt that the language code was the appropriate focus for the classroom. ${ }^{6}$

To characterize each program according to the degree to which it was communicatively oriented-that is, to place each program on a "communicative continuum"- the authors selected those features frequently mentioned in the literature on communicative language teaching and assigned scores from 1 to 5, depending on the percentage of time spent on each. The selected categories are as follows:

Group work

Focus on meaning (including management and other topics) and any combinations of form and the other content categories

Topic control by teacher and students or student alone

Use of extended text

Use of semi- and non-pedagogic materials

The scores were based on an interval scale: 0-19 percent of class time equals a score of $1 ; 20$ to 39 percent, a score of 2 , etc. Thus a class which spent 15 percent of class time on group work, 45 percent on other topics, 10 percent on activities controlled by students, 90

6 In the present study, there was insufficient time to conduct interviews with teachers. In the future, time will be provided for teacher interviews. 
percent on extended text, and 15 percent on non-pedagogic text would receive individual scores of $1+3+1+5+1$, for a total of 11 .

When these calculations were made on the data, the following order was obtained:

Core French (6)

ESL (7)

Extended French (10)

French immersion (12)

In other words, core French was the least "communicative" in terms of the categories, and immersion the most. ESL and extended French occupied a place in between. Since the purpose of this study was to determine whether the COLT scheme is capable of capturing differences in the communicative orientation of different types of classrooms, the results reported here should not be interpreted as an evaluation of the L2 programs observed. The data base is far too small to support such a conclusion, and variability between teachers within the programs was not taken into consideration.

While results of the Part B analysis confirm some of the findings of other studies on classroom interaction (e.g., Sinclair and Coulthard 1975, Naiman, Fröhlich, Stern, and Todesco 1978, Wells 1981)—for example, that students usually have the exclusive role of responding to questions which are generally pseudo-requests and that students rarely interact with each other in teacher-centered classrooms-there were some interesting differences among the programs observed in this study. In particular, students in immersion classes, where subject-matter instruction in the L2 was part of the curriculum, were given more opportunity for unrestricted language use, for sustained speech, and for giving unpredictable information. By contrast, students in core French classes generally were required to give predictable responses in restricted form and of ultraminimal length. The extended French and ESL classes tended to be situated in between core and immersion classes. These findings are consistent with the ordering of classes along the communicative continuum obtained in the analysis of the Part A features.

Second language classrooms are typically based on a rather high degree of teacher control. Learners rarely initiate discourse; they are seldom asked questions to which the teacher does not already have an answer, are expected to produce specific language forms, and are not often given the opportunity to exchange information with an interlocutor in a natural manner. Clearly, this controlled approach to language teaching is very different from the way in which languages are used and acquired in a natural setting. Therefore, it has been suggested that classes which more closely approximate the condi- 
tions for naturalistic language use may be more beneficial to the learner (Breen and Candlin 1980, Johnson and Morrow 1981, Savignon 1983). On the other hand, it should not be assumed that spontaneous classroom interaction will produce the best results in all circumstances. A number of writers recently have drawn attention to the importance of guidance and control, especially in programs which take place in a more traditional context and where the time available for practice may be limited (Brumfit 1980, Valdman 1980, Widdowson 1984).

\section{CONCLUSION}

This study was conducted to determine whether the COLT observation scheme, which was derived from a model of communicative competence and a review of current issues in communicative language teaching, was capable of capturing differences in the communicative orientation of four second language programs.

The results provide preliminary evidence that the scheme is capable of doing so-the programs did indeed differ in their communicative orientation. The development of an observation scheme capable of capturing the characteristics of different types of classrooms is an important step toward identifying what makes one set of instructional techniques more effective than another. In particular, it is hoped that the COLT scheme will assist in clarifying a number of issues relating to the current debate on the respective advantages of more communicative approaches versus more controlled, structure-based approaches to second language education.

The crucial question, which obviously cannot be answered on the basis of the present study, is what kind of communicative orientation is most beneficial for developing different aspects of second language proficiency. For example, do classes that involve students primarily in form-focused, teacher-centered activities with highly controlled language promote the development of grammatical competence? Similarly, do classes in which students spend most of their time in group activities emphasizing the expression and negotiation of meaning further the development of discourse competence and fluency in the target language? Only a study which compares instructional differences within a program and relates these differences to proficiency can provide an answer to these questions. We are currently beginning such a process-product study, in which the COLT observation scheme will be employed to examine some of the process variables and thus help in assessing the effect they have on Ianguage learning. 


\section{ACKNOWLEDGMENTS}

This study was funded by a grant from the Social Sciences and Humanities Research Council of Canada, with Patrick Allen, Jim Cummins, Birgit Harley, and Merrill Swain as principal investigators. The paper is a jointly revised version of a presentation given by Maria Fröhlich and Nina Spada at the 18th Annual TESOL Convention, Houston, March 1984.

We would like to express our thanks to the members of the Development of Bilingual Proficiency project in the Modern Language Centre at the Ontario Institute for Studies in Education, particularly to Françoise Pelletier for her participation in the classroom observation and the data coding and to Jud Burtis for his statistical assistance. Our thanks are also extended to the Toronto Board of Education and to the teachers who allowed us access to their classrooms.

\section{THE AUTHORS}

Patrick Allen is an Associate Professor in the Modern Language Centre, Ontario Institute for Studies in Education. Before moving to Toronto in 1976, he taught in the Department of Linguistics at the University of Edinburgh, Scotland. He has been involved in ESL teaching and administration in eight countries and has published extensively on applied linguistics, English for special purposes, and second language teaching methodology.

Maria Fröhlich has been a Research Officer in the Modern Language Centre at the Ontario Institute for Studies in Education since 1974. She has worked on several projects examining aspects of second language teaching and learning, and is a co-author of The Good Language Learner. She is currently working on classroom observation in the context of the Development of Bilingual Proficiency project.

Nina Spada is a Visiting Assistant Professor in the Department of Linguistics and Director of Curriculum at the English Language Institute at the University of Michigan. She recently completed her Ph.D. in applied linguistics at the Ontario Institute for Studies in Education. Her experience includes ESL instruction, teacher training, and research in second language teaching and learning.

\section{REFERENCES}

Allen, Patrick, Jim Cummins, Raymond Mougeon, and Merrill Swain. 1983. The development of bilingual proficiency. Unpublished second year report, Ontario Institute for Studies in Education, Toronto.

Allen, Patrick, Maria Fröh1ich, and Nina Spada. 1984. The communicative orientation of language teaching: an observation scheme. In On TESOL '83, Jean Handscombe, Richard A. Orem, and Barry P. Taylor (Eds.), 231-252. Washington, D. C.: TESOL.

Bialystok, Ellen, Maria Fröhlich, and Joan Howard. 1979. Studies on second language learning and teaching in classroom settings: strategies, processes, and functions. Unpublished report, Ontario Institute for Studies in Education, Toronto. 
Breen, Michael P., and Christopher N. Candlin. 1980. The essentials of a communicative curriculum in language teaching. Applied Linguistics 1(1):89-112.

Brumfit, Christopher J. 1980. From defining to designing: communicative specifications versus communicative methodology in foreign language teaching, Studies in Second Language Acquisition 3(1):1-9.

Byrne, Don. 1977. Functional comprehension. London: Longman.

Canale, Michael, and Merrill Swain. 1980. Theoretical bases of communicative approaches to second language teaching and testing. Applied Linguistics 1(1):1-47.

Dunkin, Michael J., and Bruce J. Biddle. 1974. The study of teaching. New York: Holt, Rinehart and Winston.

Fanselow, John F. 1977. Beyond Rashomon-conceptualizing and describing the teaching act. TESOL Quarterly 11(1):17-39.

Fletcher, Mark, and Roger Hargreaves. 1980. Evans functional units: activating vocabulary. London: Evans Brothers Ltd.

Hymes, Dell. 1972. On communicative competence. In Sociolinguistics, John Pride and Janet Holmes (Eds.), 269-293. Harmondsworth, England: Penguin.

Johnson, Keith, and Keith Morrow. 1979. Approaches. Cambridge: Cambridge University Press.

Johnson, Keith, and Keith Morrow (Eds.). 1981. Communication in the classroom. London: Longman.

Long, Michael H. 1980. Inside the "black box": methodological issues in classroom research on language learning. Language Learning 30(1):1-42.

Mitchell, Rosamond, Brian Parkinson, and R. Johnstone. 1981. The foreign language classroom: an observational study. Stirling Educational Monographs No. 9. Stirling, Scotland: University of Stirling, Department of Education.

Moskowitz, Gertrude. 1970. The foreign language teacher interacts. Chicago: Association for Productive Teaching.

Moskowitz, Gertrude. 1971. Interaction analysis-a new modern language for supervisors. Foreign Language Annals 5(2):211-221.

Munby, John. 1978. Communicative syllabus design. Cambridge: Cambridge University Press.

Naiman, Neil, Maria Fröhlich, Hans H. Stern, and Angie Todesco. 1978. The good language learner. Toronto: Ontario Institute for Studies in Education.

Savignon, Sandra J. 1983. Communicative competence: theory and classroom practice. Reading, Massachusetts: Addison-Wesley.

Simon, Anita, and E. Gil Boyer. 1974. Mirrors for behavior III: an anthology of classroom observation instruments, Wyncote, Pennsylvania: Communication Materials Center.

Sinclair, John M., and R. Malcolm Coulthard. 1975. Towards an analysis of discourse. London: Oxford University Press.

Ullmann, Rebecca, and Esther Geva. 1982. The target language observation scheme (TALOS). York Region Board of Education, Core French Evaluation Project. Unpublished report, Ontario Institute for Studies in Education, Toronto. 
Valdman, Albert. 1980. Communicative ability and syllabus design for global foreign language courses. Studies in Second Language Acquisition 3(1):81-96.

Wells, Gordon. 1981. Learning through interaction: the study of language development. Cambridge: Cambridge University Press.

Widdowson, Henry G. 1984, Educational and pedagogic factors in syllabus design. In General English syllabus design, Christopher J. Brumfit (Ed.), 23-27. ELT Documents 118. Oxford: Pergamon Press.

\section{APPENDIX A \\ COLT Observation Scheme: Definition of Categories}

The COLT observation scheme is divided into two parts. Part A describes classroom events at the level of episode and activity, while Part B analyzes the communicative features of verbal exchanges between teachers and students or among students themselves as they occur within each activity.

Part A: Classroom Events

I. Activity

The first parameter is open-ended; no predetermined descriptors have to be checked off by the observer. Each activity and its constituent episodes are separately described: e.g., drill, translation, discussion, game, and soon (separate activities); alternatively, teacher introduces dialogue, teacher reads dialogue aloud, students repeat dialogue parts after teacher (three episodes of one activity).

II. Participant Organization

This parameter describes three basic patterns of organization:

A. Whole Class

1. Teacher to student or class, and vice versa (One central activity led by the teacher is going on; the teacher interacts with the whole class and/or with individual students.)

2. Student to student, or student(s) to class (Students talk to each other, either as part of the lesson or as informal socializing; one central activity led by a student may be going on, e.g., a group of students act out a skit with the rest of the class as the audience. )

3. Choral work by students (The whole class or groups participate in the choral work, repeating a model provided by the textbook or teacher. )

B. Group work

1. All groups at work on the same task

2. Groups at work on different tasks

C. Individual seat work (Students work on their own, all on the same task or on different tasks. )

D. Group/individual work (Some students are involved in group work; others work on their own.)

COMMUNICATIVE ORIENTATION OF L2 CLASSROOMS 


\section{Content}

This parameter describes the subject matter of the activities, that is, what the teacher and the students are talking, reading, or writing about or what they are listening to. Three major content areas have been differentiated, along with the category Topic Control:
A. Management
1. Procedural directives

2. Disciplinary statements

B. Explicit focus on language

1. Form (explicit focus on grammar, vocabulary, or pronunciation)

2. Function (explicit focus on illocutionary acts such as requesting, apologizing, and explaining)

3. Discourse (explicit focus on the way sentences combine into cohesive and coherent sequences)

4. Sociolinguistics (explicit focus on the features which make utterances appropriate for particular contexts)

C. Other topics (the subject matter of classroom discourse, apart from management and explicit focus on language)

1. Narrow range of reference (This subcategory refers to the immediate classroom environment and to stereotyped exchanges such as "Good morning" or "How are you?" which have phatic value but little conceptual content. Included in this category are routine classroom references to the date, day of the week, weather, and so on.)

2. Limited range of reference (Topics in this subcategory refer to information beyond the classroom but still conceptually limited: movies, holidays, school topics such as extracurricular activities, and topics which relate to the students' immediate personal and family affairs, e.g., place of residence, number of brothers and sisters. and so on:)

3. Broad range of reference (Topics of broad range go well beyond the classroom and immediate environment and include reference to controversial public issues. world events. abstract ideas, reflective personal information, and other academic subject matter, such as math or geography. )

D. Topic control (Who selects the topic that is being talked aboutthe teacher, the student, or both?)

IV. Student modality

This section identifies the various skills involved in a classroom activity. The focus is on the students, and the purpose is to discover whether they are listening, speaking, reading, or writing, or whether these activities are occurring in combination. The category Other covers such activities as drawing, modeling, acting, or arranging classroom displays.

V. Materials

This parameter describes the materials used in connection with classroom activities. 
A. Type of materials

1. Text (written)

a. Minimal (e. g., captions, isolated sentences, work lists)

b. Extended (e.g., stories, dialogues, connected paragraphs)

2. Audio

3. Visual

B. Source/purpose of materials

1. Pedagogic (specifically designed for L2 teaching)

2. Non-pedagogic (materials originally intended for nonschool purposes)

3. Semi-pedagogic (utilizing real-life objects and texts but in a modified form)

C. Use of materials

1. Highly controlled (close adherence to materials)

2. Semi-controlled (occasional extension beyond the restrictions imposed by the materials).

3. Minimally controlled (materials as a starting point for ensuing conversation, which may cover a wide range of topics)

Part B: Communicative Features

I. Use of target language

A. Use of first language (Ll)

B. Use of second language (L2)

II. Information gap

This feature refers to the extent to which the information requested and/or exchanged is unpredictable, i.e., not known in advance.

A. Requesting information

1. Pseudo (The speaker already possesses the information requested, )

2. Genuine (The information requested is not known in advance.)

B. Giving information

1. Relatively predictable (The message is easily anticipated in that there is a very limited range of information that can be given. In the case of responses, only one answer is possible semantically, although there may be different correct grammatical realizations.)

2. Relatively unpredictable (The message is not easily anticipated in that a wide range of information can be given. If a number of responses are possible, each can provide different information. )

III. Sustained speech

This feature is intended to measure the extent to which speakers engage in extended discourse or restrict their utterances to a minimal length of one sentence, clause, or word.

A. Ultraminimal (utterances consisting of one word-coded for student speech only)

B. Minimal (student utterances consisting of one clause or sentence, teacher utterances consisting of one word)

C. Sustained speech (utterances longer than one sentence or consisting of at least two main clauses)

COMMUNICATIVE ORIENTATION OF L2 CLASSROOMS 
IV. Reaction to code or message

This feature refers to a correction or other explicit statement which draws attention to the linguistic form of an utterance.

V. Incorporation of preceding utterances

A. No incorporation (no feedback or reaction given)

B. Repetition (full or partial repetition of previous utterance/s)

C. Paraphrase (completion and/or reformulation of previous utterance/s)

D. Comment (positive or negative comment on, but not correction of, previous utterance/s)

E. Expansion (extension of the content of preceding utterance/s through the addition of related information)

F. Elaboration (requests for further information related to the subject matter of the preceding utterance/s)

VI. Discourse initiation

This feature measures the frequency of self-initiated turns (spontaneously initiated talk) by students.

VII. Relative restriction of linguistic form

A. Restricted use (the production or manipulation of one specific form, as in a transformation or substitution drill)

B. Limited restriction (a choice of more than one linguistic form but in a very narrow range, e.g., responses to yes/no questions, statements about the date, time of day, and so on)

C. Unrestricted use (no expectation of any particular linguistic form, as in free conversation, oral reports, or personal diary writing) 

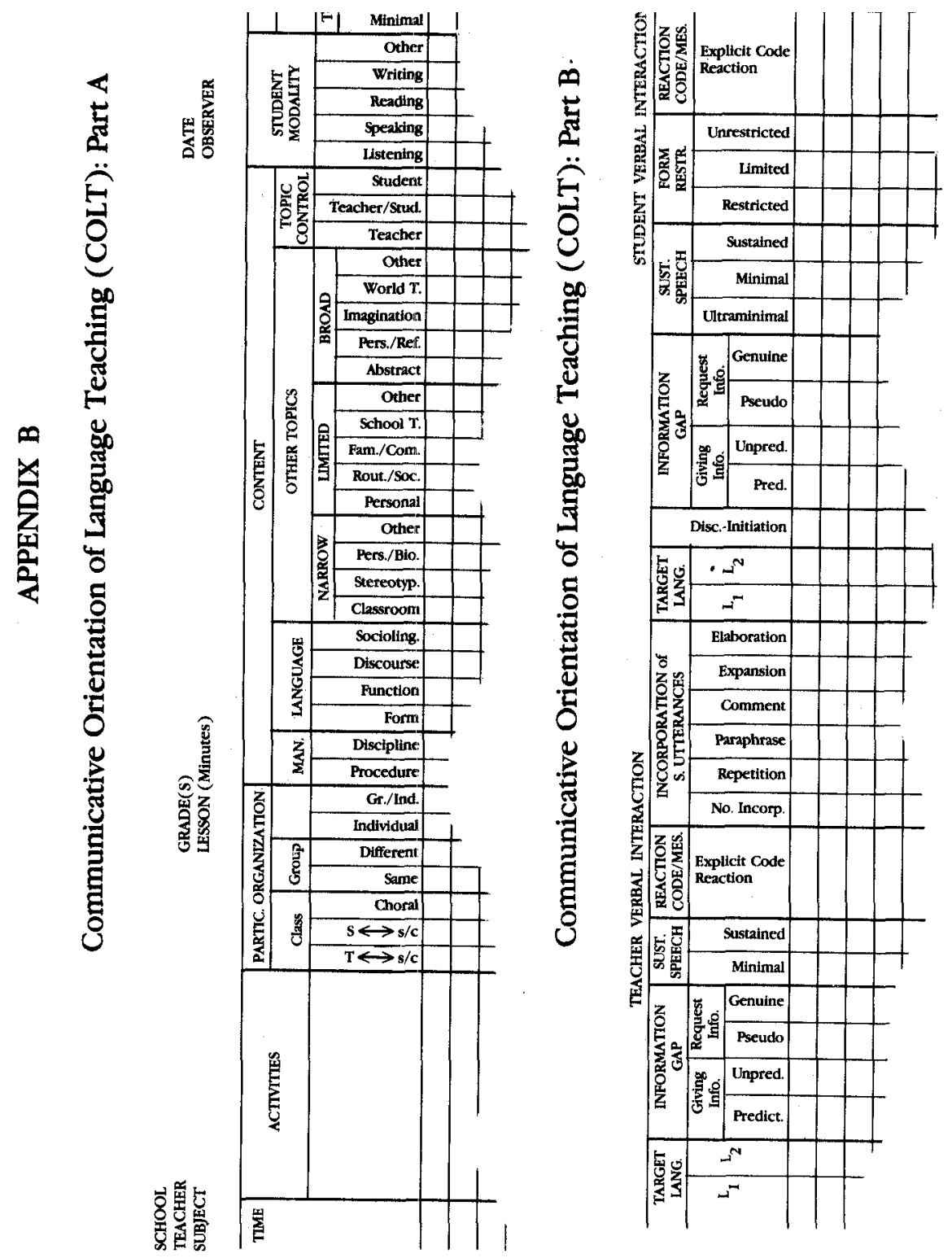